\title{
Una Constitución Mundial en clave de derechos humanos desde la periferia del
}

mundo

\section{A World Constitution in the key of human rights from the periphery of the world}

Autores: Javier Antonio Tobar Rodríguez, Manuel Eduardo Rodríguez Arias. 


\title{
UNA CONSTITUCIÓN MUNDIAL EN CLAVE DE DERECHOS HUMANOS DESDE LA PERIFERIA DEL MUNDO
}

\author{
A World Constitution in the key of human rights from the periphery of the world \\ Uma Constituição Mundial em termos de direitos humanos da periferia do mundo
}

\author{
Javier Antonio Tobar Rodrígueza ${ }^{\mathbf{a}}$ \\ javiercompliance@gmail.com
}

\author{
Lic. Manuel Eduardo Rodríguez Arias ${ }^{b}$ \\ manuel.rodriguez@utec.edu.sv
}

Recepción: 09 de noviembre 2020

Aceptación: 25 de noviembre 2020

\section{RESUMEN}

El objetivo del presente artículo fue reflexionar sobre la situación actual del constitucionalismo en relación a la pandemia desde la periferia, es decir Centroamérica y, especialmente, El Salvador en relación al exterior del mundo. Se empleó la observación directa de la realidad, principalmente de los acontecimientos actuales, recientes y previos al acaecimiento de la pandemia, detectando ideas en común con las que pretendemos sostener que debe reflexionarse sobre el futuro del género humano. Así como, que el instrumento de cohesión jurídico óptimo es una constitución global que contenga mínimos a manera de un instrumento de Derecho uniforme. La investigación se toma la licencia de pensar libremente y traspasar los límites de la imposibilidad política requerida para realizar los cambios constitucionales que suponen desdibujar fronteras para reconocer derechos mínimos de la humanidad. El resultado final de esta empresa no puede ser más que reconocer derechos mínimos universales, principalmente de las poblaciones más vulnerables del planeta. La puesta en práctica de los resultados supone emplear una dosis alta de imaginación, dejando atrás ideas preconcebidas y ampliando el horizonte de propuesta, necesaria en cuanto se concreten derechos de la humanidad.

\section{PALABRAS CLAVES}

Inmigración; globalización; constitución; derechos; uniforme.

\section{ABSTRACT}

The objective of this article was to reflect on the current situation of constitutionalism in relation to the pandemic from the periphery, that is, Central America and especially El Salvador in relation to the outside of the world. We use the direct

\footnotetext{
* Artículo de reflexión.

a. Doctor y Máster en Derecho por la Universidad Carlos III de Madrid Profesor hora clase Universidad Tecnológica de El Salvador (UTEC).

https://orcid.org/0000-0003-4881-6992

b. Director de la Escuela de Derecho Universidad Tecnológica de El Salvador (UTEC) Doctorando en Derecho Privado Universidad José Matías Delgado

https://orcid.org/0000-0003-4802-1241
} 
observation of reality, especially of the events that occurred recently and prior to the occurrence of the pandemic and coexisting with it, detecting ideas in common with which we intend to maintain that the future of the human race should be reflected upon and that the instrument optimal legal cohesion is a global constitution that contains minimums as an instrument of uniform law. At this point of no return in the history of humanity, we grant ourselves license to think freely and go beyond the limits of the political impossibility required to make constitutional changes, which involves blurring borders, to recognize minimum rights of humanity. The result of this mission cannot be more than to recognize universal minimum rights, mainly of the most vulnerable populations on the planet. Putting the results into practice implies using a high dose of imagination, leaving behind preconceived ideas and broadening the horizon of the proposal, which is necessary as soon as the rights of humanity are made concrete.

\section{KEYWORDS}

Immigration; globalization; constitution; rights; uniform.

\section{RESUMO}

O objetivo deste artigo foi refletir sobre a situação atual do constitucionalismo em relação à pandemia da periferia, ou seja, a América Central e, especialmente, El Salvador em relação ao exterior. Utilizouse a observação direta da realidade, principalmente de eventos atuais, recentes e anteriores à ocorrência da pandemia, detectando ideias em comum com as quais pretendemos argumentar que o futuro da humanidade deve ser refletido. Bem como, que o instrumento ótimo de coesão jurídica é uma constituição global que contém mínimos na forma de um instrumento uniforme de lei. A investigação tira licença para pensar com liberdade e ultrapassar os limites da impossibilidade política exigida para realizar as mudanças constitucionais que envolvem esmaecer as fronteiras para o reconhecimento dos direitos mínimos da humanidade. 0 resultado final desta empresa não pode ser mais do que reconhecer direitos mínimos universais, principalmente das populações mais vulneráveis do planeta. A concretização dos resultados envolve muita imaginação, deixando para trás ideias pré-concebidas e ampliando o horizonte da proposta, necessária assim que os direitos da humanidade forem realizados.

\section{PALAVRAS-CHAVE}

Imigração; globalização; Constituição; direitos; uniforme.

\section{SUMARIO}

Introducción

1. El problema global del ejercicio de los derechos que deslegitima el ejercicio constitucional sectorizado.

2. El Salvador y su control de constitucionalidad normativo a consecuencia del COVID-19.

2.1. Marco jurídico en materia de salud y protección constitucional.

2.2. Regímenes de emergencia y controles constitucionales.

2.3. Afectaciones de derechos constitucionales y humanos durante la pandemia COVID-19.

3. Construcción del constitucionalismo desde las premisas existentes.

3.1. Constitucionalismo Regional en germen desde Centroamérica.

3.2. Reconocimiento de la protección de derechos humanos desde los tratados y jurisprudencia americana.

3.3. Los medios de comunicación y tecnológicos como instrumento de participación constitucional.

4. Puesta en práctica del Constitucionalismo uniforme desde los principios comunes (a manera de esbozo).

4.1. Mínimo común vital (Alberto Masferrer). 4.2. El llamado a la intervención externa a solventar conflictos internos.

4.3. Un nuevo constitucionalismo desde la ciudadanía cosmopolita.

4.4. Servicios sociales de confianza a

disposición de la diáspora.

Conclusiones.

Referencias bibliográficas. 


\section{INTRODUCCIÓN}

En el presente artículo se abordarán reflexiones que combinan una realidad, y ficción, jurídica que quizá no la verán nuestros ojos en un futuro. Ello es fruto de vislumbrar los resultados devenidos de los últimos acontecimientos originados por el COVID-19, y otras realidades que están llevando al Mundo a sus límites. Por todos es sabido que hoy más que nunca el género humano tiene al mundo en sus manos una bomba nuclear, la cual no es más que uno de los objetos que pueden hacer cambiar el futuro de la humanidad.

En el trabajo emplearemos la expresión "periferia del mundo" para localizar en el mapa a los países que no son las primeras potencias mundiales en el ramo económico, tecnológico, etc. y que inciden en las políticas mundiales. Ubicamos a El Salvador en esta periferia, posición que puede extrapolarse a otros países. Las potencias mundiales son países centros del mundo en cuanto a que constituyen ejes de muchos de los actos, u omisiones, que inciden a nivel planetario, y de cuyas decisiones depende el ejercicio de los derechos humanos.

Nuestro aporte va encaminado a recopilar algunas ideas que, articuladas debidamente, pueden considerarse como un reflejo de algunas ideas compartidas por el profesor italiano Ferrajoli, en un vídeo difundido mundialmente, y que, a su vez, constituye al parecer un sentimiento compartido por muchos. A la vez recuerda las ideas sostenidas por otros connotados autores universales como Kant y Humboldt. Nos referimos a la reconsideración de las relaciones del género humano, al apoyo de una ciudadanía cosmopolita y a la organización de una sociedad universal más humanizada.

Advertimos y hacemos hincapié a los lectores que No pretendemos "desarrollar" las ideas del profesor Ferrajoli, solamente retomar algunas. Debido, principalmente, a que ha sido la voz actual y autorizada de muchas mentes, según las expuso, de viva voz, en los foros virtuales que se abrieron desde Latinoamérica, de la mano del profesor
Miguel Carbonell, de México, y Pedro Grández Castro, organizado por Palestra, Perú, el 14 de mayo de 2020, disponible en YouTube, para que él expusiera su visión del constitucionalismo en tiempos de pandemia.

De ahí que el alcance del artículo es más modesto de lo que pudiera parecer, no se tiene más intención que desahogar lo que se percibió, previo y durante la pandemia, en la sociedad salvadoreña y vecinas. Por eso mismo, no se pretende desarrollar una tesis del profesor Ferrajoli, ni desarrollar un principio o regla, para cuyos supuestos tuviéramos que haber citado muchos más recursos bibliográficos.

En ese sentido, la originalidad del trabajo se encamina en recoger algunos ejemplos que la pandemia ha generado, como las fricciones legales y constitucional sucedidas en El Salvador entre la ciudadanía que reclama libertades restringidas por la implementación de medidas sanitarias, y las respuestas que las autoridades han proporcionado concediéndolas 0 restringiéndolas.

La pandemia ha generado problemas económicos, desempleo y al parecer incrementa el deseo de la población por migrar. El uso de las redes sociales en tiempos de pandemia ha sido vital para que las personas se manifiesten al respecto. El mismo medio podría servir, entre otros, para construir un instrumento de soft law que reivindique un "menú" de derechos humanos o pertenecientes a la nación humana y que se reconozca en una "constitución mundial".

Como venimos señalando, este trabajo no pretende agotar en líneas aspectos tan sustanciales como la construcción de una Constitución, ni enumerar los derechos que debería contener, por eso, exponemos las ideas dejando abierto el debate.

\section{EL PROBLEMA GLOBAL DEL EJERCICIO DE LOS DERECHOS QUE DESLEGITIMA EL EJERCICIO CONSTITUCIONAL SECTORIZADO}


En el apartado en cuestión nos referiremos a una serie de problemas de la existencia humana, aunque con referencia concreta al área centroamericana, especialmente a El Salvador. Su exposición tiene por objeto colocar al lector en el contexto socioeconómico regional $\mathrm{y}$, por el cual, más adelante proporcionaremos argumentos tendentes a reflexionar sobre la propuesta del distinguido profesor Ferrajoli en cuanto a la configuración de un constitucionalismo universal, por el que se reconozcan derechos mínimos, para lo que puede echarse mano de aquellos reconocidos por los diversos instrumentos de derechos humanos.

$\mathrm{Al}$ respecto, creemos que no es posible sostener la protección de los derechos constitucionales de las personas, o solo de los ciudadanos, sin considerar la protección de los derechos humanos de la colectividad universal. Es decir, de la humanidad entera. Sostener lo contrario carece de sentido si se considera que los derechos humanos deben ser la premisa de interpretación, y aplicación, de los derechos constitucionales. Recordemos que muchas constituciones reconocen el deber de entender los derechos constitucionales desde los derechos humanos, por ejemplo, la española, la argentina y por supuesto, la influencia que los tribunales de derechos humanos a través de su jurisprudencia en los derechos internos de los países que gravitan sobre su esfera de aplicación. En otras palabras, no podemos pretender estar disfrutando de un estilo de vida confortable, ignorando completamente las necesidades de otros, cuando estamos en posición de poder ayudarlos tendiendo puentes de diálogo y, sobre todo, decisión. Dicho de otro modo, no es posible que moralmente pueda sostenerse que desde otros Estados puedan disfrutar de un nivel de vida digno cuando en otros no es posible para muchas personas obtener ni siquiera lo mínimo de supervivencia.

$\mathrm{Al}$ respecto, recuérdese una de las lecciones de vida obtenidas de la II Guerra Mundial, que hace considerar la hipótesis de que no es posible que el exterminio de un colectivo humano, los judíos, haya pasado desapercibido por muchos, incluso por la Iglesia Católica. Es muy probable que muchos pecaran por omisión (MAYOR FERRÁNDIZ, p. 1 y 2 ; FERNÁNDEZ, p. 359).

Partimos de la creencia de la total fragilidad e interdependencia de todos en el mundo, que es un hecho notorio, cada día más lo evidenciamos con hechos que suceden en el otro extremo del globo terráqueo y repercuten planetariamente. Por ejemplo, las arenas del Sahara llegan cada año a Centroamérica, lo que hace un par de décadas no constituía hecho reportado; la catástrofe de Chernóbil en la antigua Unión de Repúblicas Socialistas Soviéticas alcanzó Alemania y otros países europeos. Nuestra salud y vida depende de la salud de los otros y del planeta. La pandemia tiene un carácter global y no es la primera que sucede, pero sí la que más repercusiones ha tenido por razones evidentes.

Bajo una perspectiva global, creemos que la nacionalidad debe concebirse más pragmáticamente como un perfil susceptible de cambiarse según las necesidades del humano, por eso el inmigrante obtiene nueva nacionalidad que le garantice el goce de los derechos humanos en cuanto tiene la oportunidad de poder obtenerla, lo que se traduce en términos de políticas públicas en que el Estado receptor del migrante absorbe la obligación de cubrir la protección de los derechos humanos de quien en un primer momento no nació siendo su nacional.

La realidad presente, de la existencia de dobles o múltiples nacionales en cabeza de un individuo, obedece a ese interactuar humano cada vez más global y al empuje que las migraciones han tenido por varias razones: demográficas, naturales, bélicas, ideológicas y económicas.

En ese sentido, una libertad económica sin control genera costos sociales a las personas. Por ejemplo, genera migraciones y pobreza, por eso mismo los Estados recientemente controlan el ejercicio de prácticas financieras que generaron catástrofes económicas a nivel mundial, tal como la que sucedió en el año 2008 al 2012 en Estados Unidos y Europa. 
Hay que mencionar que hoy más que nunca nos sentimos existencialmente más unidos a otros no importando la distancia física debido al empleo de las tecnologías $\mathrm{y}$ las telecomunicaciones, los medios de transportes constituyen una realidad.

Asimismo, desde Centroamérica y El Salvador, territorio frágil, susceptible a sufrir catástrofes climáticas y telúricas, con alta tasa demográfica habitando en territorios que pertenecen naturalmente a la rica e indomable naturaleza que lucha por conservar su espacio contra el humano, creemos que ello genera migraciones que pueden ser aprovechadas en territorios llanos, valles o meseta alejados del peligro de los accidentes topográficos.

Sí creemos en el constitucionalismo como manifestación de la solidaridad humana mundial frente al egoísmo manifestado en sectarismos separatistas.

Por el momento, los Tratados de Libre Comercio han apostado generalmente a la protección de la circulación internacional de productos, pero ¿dónde queda el humano? No siempre el humano se le ha permitido circular con igual velocidad y facilidad que a las mercaderías. Y, además, dichos tratados, y la estructura económica actual, han quedado aún más expuestos por la pandemia, pues ha demostrado que la interdependencia de la economía por la implementación de las cadenas de producción puede generar paralización de empresas que requieren insumos producidos en otro lado del planeta, donde la pandemia generó estragos y cese de la producción.

Mientras cada Estado defiende a sus nacionales frente a los desafíos de la pandemia u otros, debemos pensar que así como el COVID-19, otros retos se presentarán a futuro. Piénsese en, por ejemplo, riesgos sanitarios que pudieran surgir de las exploraciones a otros planetas realizados por las potencias mundiales que los visitan y realizan experimentos en ellos, pudiendo traer consigo restos de microorganismos que constituyan un peligro para nuestra existencia sea liberado intencional o accidentalmente en la tierra.

Problemas globales con soluciones globales. Reconocer instituciones que provean garantías planetarias. Por ejemplo, la Organización Mundial de la Salud debe reforzarse para promover la prevención de ataques a la salud. La sanidad privada obligatoria en sociedades poco equitativas condena a las personas a la muerte, por el contrario, la sanidad pública que garantice a todos salud y vida es un derecho humano.

Más abajo expondremos la respuesta sociopolítica-jurídica del Estado salvadoreño y la sociedad frente al COVID-19.

\section{EL SALVADOR Y SU CONTROL DE CONSTITUCIONALIDAD NORMATIVA CONSECUENCIA DEL COVID-19}

En este apartado veremos que desde su surgimiento, el COVID-19 ha generado drásticas transformaciones en la vida, tanto como individuos como colectivos, y El Salvador ha sido uno de tantos países afectados con esta nueva realidad. La cual, ha puesto a prueba a los diferentes órganos del Estado, quienes, como en muchos países, no han trabajado de forma armónica en un solo frente contra la realidad de salud. El Salvador, como tantos otros Estados, ha restringido -e incluso suspendido- derechos de libertad ambulatoria, cerrado fronteras terrestres, marítimas y áreas, incurrido en restricciones de libertad ambulatoria y en centros de cuarenta, etc.

El país cuenta con un marco jurídico en normativa secundaria así como constitucional. No obstante, ello generó una hiperproducción normativa, especialmente proveniente del ejecutivo, la cual no siempre concordaba con la desarrollada por la Asamblea legislativa. Dicha oposición y choque de planteamientos normativos tuvo una constante y necesaria intervención de la Sala Constitucional de la Corte Suprema de Justicia, el órgano competente para dirimir las controversias constitucionales. Por eso, en el presente apartado se abordará 
lo relativo al control de constitucionalidad sobre la hiperproducción normativa de la legislación excepcional, consecuencia de la declaratoria de emergencia de salud del COVID-19.

Luego de que la Organización Mundial de la Salud (OMS) declaró que el brote del SARS-CoV-2 debía ser considerado como una emergencia de salud pública de importancia internacional (Organización Panamericana de la Salud, 30 de enero de 2020), muchos Estados adoptaron medidas para prevenir contagios masivos. Dichas medidas fueron reforzadas desde el 11 de marzo del mismo año, cuando la OMS declaró que la enfermedad producida por el virus podía ser considerada «pandemia» (OMS, 11 de marzo de 2020). De igual forma, se hizo hincapié en la perdurabilidad que podría tener dicha pandemia.

El Centro para el Control y la Prevención de Enfermedades (CDC, por sus siglas en inglés) planteó que las pandemias de influenza, a cuyo género pertenece la COVID-19, se describen mediante un marco de intervalos de una pandemia. Se compone de las fases de investigación de casos de: infecciones, reconocimiento de un potencial aumento, iniciación de una ola pandémica, aceleración de dicha ola, desaceleración y preparación para las olas futuras.

El Estado de la República de El Salvador, en uso de sus facultades constitucionales, tras la declaración de la OMS de pandemia por el Coronavirus (COVID-19), estableció protocolos para prevenir y frenar el ingreso de la pandemia. Las autoridades optaron por restringir derechos reconocidos no solo en la Constitución, sino también en tratados del Derecho Internacional de los Derechos Humanos (Convención de Viena sobre el Derecho de los Tratados, 1969, art. 26). Incluso se aprobó un estado de excepción por medio del Decreto Legislativo 594, de 15 de marzo de 2020, que fue prorrogado en una ocasión por el Decreto Legislativo 611, de 29 de marzo de 2020.

En el contexto de la pandemia las autoridades salvadoreñas han restringido, entre otros: (i) la libertad de circulación (arts. 22.1 de la Convención Americana sobre Derechos Humanos, «CADH», y 12.1 del Pacto Internacional de Derechos Civiles y Políticos, «PIDCP»); (ii) la libertad personal (arts. 7.1 de la CADH y 9.1 del PIDCP); la libertad de residencia (arts. 22.1 de la CADH y 12.1 del PIDCP); y el derecho de salir e ingresar al propio país (arts. 22.5 de la $\mathrm{CADH}, 12.4$ del PIDCP, en relación con la Observación General 27 del Comité de Derechos Humanos, y con el art. 10.1 y 2 de la Convención sobre los Derechos del Niño, «CDN»).

Sin embargo, el contexto es, y ha sido, propicio para que en Estados con sistemas de salud tan precarios como el nuestro, con capacidades limitadas para responder de manera efectiva frente a una pandemia de esta envergadura, y donde además se tutelan de manera deficiente los derechos económicos, sociales, culturales y ambientales, se hayan planteado reclamos por vulneraciones al derecho a la salud, al trabajo, a la seguridad social y a la educación (art. 26 de la CADH en relación con los arts. 10, 6, 9 y 13 del Protocolo de San Salvador, arts. 12.1 y 2, 6, 9 y 13 del Pacto Internacional de Derechos Económicos, Sociales y Culturales, y art. 24.1 y 2 de la $C D N$ ), por mencionar algunos.

\subsection{Marco jurídico en materia de salud y protección constitucional}

Mediante el empleo del marco constitucional de los derechos fundamentales, se han definido los derechos fundamentales como aquellas facultades o poderes de actuación reconocidos a toda persona humana como consecuencia de exigencias jurídicas derivadas de su dignidad, libertad e igualdad inherentes. Las cuales, han sido normativizadas constitucionalmente $\mathrm{y}$, en virtud de dicha positivación, desarrollan una función de fundamentación material de todo el ordenamiento jurídico. Consecuencia de ello, ostentan supremacía y la protección reforzada de las que goza la Constitución (sentencia de 23 de marzo de 2001, inconstitucionalidad 8-97; y sentencia de 17 de noviembre de 2015, inconstitucionalidad 105-2014). 
Dentro de los derechos fundamentales que deben ser garantizados, en primer término, por el Estado se encuentra el derecho a la salud. En la normativa constitucional salvadoreña, la cual está regulada en los artículos 65 y siguientes de dicha carta magna, se determina que la salud es un bien público el cual el Estado se encuentra en la obligación de conservar y restablecer, debiendo determinar la política nacional de salud, asegurar su gratuidad y contener un carácter preventivo y no solo de restablecimiento; debiendo velar por aquellas personas que, por su edad, incapacidad física, mental, sean inhábiles para el trabajo.

En relación al derecho a la salud, la jurisprudencia constitucional ha desarrollado tres elementos esenciales que deben componer su ámbito de protección:

1. La adopción de medidas para su conservación. La salud requiere de una protección estatal activa y pasiva contra los riesgos exteriores que puedan ponerla en peligro. De ahí que se deban implementar medidas que, desde el punto de vista positivo, tiendan a la prevención de cualesquiera situaciones que la lesionen o que restablezcan dicha condición $\mathrm{y}$, desde el punto de vista negativo, que eviten la comisión de cualquier acto que provoque su menoscabo;

2. La asistencia médica. Ello a cómo debe garantizarse a toda persona la posibilidad de disponer y acceder al sistema o red de servicios de salud.

3. La vigilancia de los servicios de salud, que implica crear instituciones y mecanismos que vigilen y controlen la seguridad e higiene de las actividades profesionales vinculadas con ella (sentencias de 21 de septiembre de 2011 y 28 de mayo de 2013, amparos 1662009 y 310-2013).

Tal derecho fundamental exige, por su propia connotación, que el tipo de asistencia médica ofrecida en el sistema de salud del país sea integral en todo su contexto, con la obligación del Estado y de los servicios de salud prestar, con diligencia y cuidado la atención médica adecuada a las personas enfermas que lo requieran o necesiten. De conformidad con el criterio de accesibilidad a la salud - tal como se ha señalado en la Observación general $N^{\circ} 14$ del Comité de Derechos Económicos, Sociales y Culturales de Naciones Unidas - todas las personas tienen derecho a acceso físico, social y económico a servicios adecuados de prevención, atención y rehabilitación de la salud.

La salud es proclamada como un derecho fundamental inherente a las personas, encuentra su sentido más concreto en la exigencia a los poderes públicos, a que toda persona tenga potestad y acceso a recibir asistencia médica y tratamiento terapéutico adecuado para aliviar sus afecciones, sean fisiológicas o psicológicas. Por cuanto, la salud representa una de las condiciones esenciales que posibilita a los sujetos tener una existencia física digna y, con ello, desarrollar plenamente su personalidad y potencialidades. Lo cual, es en esencia la razón de ser del estado, de conformidad al art. 1 de la Constitución de la República de El Salvador.

Ahora bien, debe señalarse que el abordaje, tanto de la salud individual como de la colectiva de los habitantes de la República, no está exento del control del derecho. La injerencia de las decisiones sobre la salud, tomadas por las autoridades respectivas, pueden incidir sobre otros derechos fundamentales de la población. Por lo que dichas decisiones se encuentran sometidas a control judicial.

En ese orden de ideas, El Salvador cuenta con un desarrollo de dicho derecho en la normativa secundaria. La cual, se concentra en el Código de salud, que tiene por objeto desarrollar los mandatos constitucionales, así como las convenciones suscritas y ratificadas por el estado en materia de salud. Ellas relacionadas con la salud pública y asistencia social de los habitantes de la República; las normas para la organización 
funcionamiento y facultades del Consejo Superior de Salud Pública, del Ministerio de Salud Pública y Asistencia Social y demás organismos del Estado; servicios de salud privados; y las relaciones de éstos entre sí en el ejercicio de las profesiones relativas a la salud del pueblo (código de salud http:// asp.salud.gob.sv/regulacion/pdf/ley/ codigo_de_salud.pdf )

En el art 40, y siguientes de dicho ordenamiento jurídico, se establece que El Ministerio de Salud Pública y Asistencia Social es el Organismo encargado de determinar, planificar y ejecutar la política nacional en materia de Salud, dictar las normas pertinentes, organizar, desarrolla, los mandatos constitucionales declarando de interés público, las acciones permanentes del Ministerio contra las enfermedades transmisibles, entre otros. Para ello, todas aquellas instituciones públicas o privadas competentes deberán prestarle su colaboración.

De igual forma establece en su art. 136, y siguientes, todo lo referente al tratamiento de las cuarentenas, observación, aislamiento, creación de albergues, tratamiento de personas infectadas y en observación, vigilancia, como deberán ser abordados el confinamiento, la sanitización y procedimientos de desinfección. Así como el control de las empresas dedicadas a ello.

La norma secundaria aborda cómo debe procederse en caso de epidemia o amenaza de ella, estableciendo que el Órgano Ejecutivo en el Ramo de la Salud Pública (Ministerio de Salud Pública), podrá declarar zona epidémica, sujeta a control sanitario, cualquier porción del territorio nacional que dicho Órgano designe. Y adoptará las medidas extraordinarias que aconseje, y por el tiempo que la misma señale, para prevenir el peligro, combatir el daño y evitar su propagación.

Lo anterior abarca lo contemplado en los arts. 142 y siguientes CS (Código de salud), en las que se faculta a dichas autoridades a ordenar o realizar con carácter obligatorio la práctica periódica de exámenes colectivos de salud y toda medida de carácter preventivo que se estime conveniente de acuerdo a las necesidades de la conservación de la salud poblacional. Debiendo todas las personas naturales o jurídicas, las instituciones públicas y descentralizadas, prestar toda la colaboración que solicite el Ministerio de Salud Pública.

En caso de epidemia, o en este caso de la pandemia declarada por la OMS y reconocida por el gobierno de El Salvador, en la cual se consideró como una calamidad grave que podría haber afectado la salud y la vida de las personas, los arts. 184 y siguientes, faculta al ministerio de Salud a: a) La atención inmediata e integral de los afectados. b) El traslado a los centros de asistencia médica de los que ameriten. c) Dictar las medidas necesarias para el mantenimiento de los servicios básicos de saneamiento. ch) Dictar y desarrollar medidas de prevención de epidemias.

De igual forma, toda institución de salud pública o privada tiene la obligación de crear un plan de emergencia para el tratamiento de la pandemia con los protocolos de bioseguridad.

Todo lo anterior se concatena con la Ley de Protección Civil, Prevención y Mitigación de Desastres (LPCPMD), la cual, como normativa, tiene por objeto prevenir, mitigar $\mathrm{y}$ atender en forma efectiva los desastres naturales y antrópicos en el país. Además de desplegar el servicio público de protección civil para garantizar la vida e integridad física de las personas, así como la seguridad de los bienes privados y públicos. La cual, se vincula con el derecho a la salud que impone un mandato al legislador de aprobar medidas para que la misma sea conservada. Dicho mandato tiene una referencia legal en el art. 24 de la Ley de Protección Civil, Prevención y Mitigación de Desastres (LPCPMD). El estado de emergencia a que se refiere el precepto opera en parte, o en todo el territorio nacional, previa declaración de la Asamblea Legislativa a petición del presidente de la república, a menos que la Asamblea Legislativa no estuviere reunida. 
Una de las consecuencias de la reacción estatal salvadoreña, ante la declaración de emergencia por la pandemia, ha sido la hiperproducción normativa en el estado de excepción. Pues, se han pronunciado al menos 90 cuerpos normativos que incluyen Decretos Legislativos que emanan de la Asamblea Legislativa y Decretos Ejecutivos que el presidente de la república emitió, además de otras normas que otras administraciones públicas emitieron. Escapa de estas líneas hacer una referencia puntual a todos los decretos, algunos transitorios, los cuales fueron expulsados del ordenamiento jurídico en su momento por los órganos competentes en razón a su incongruencia con la normativa constitucional en el ejercicio de los controles de dicha naturaleza.

\subsection{Regímenes de emergencia y controles constitucionales}

La Constitución de la República de El Salvador reconoce dos formas básicas para lidiar con situaciones de emergencia:

I. El régimen de excepción, previsto y sancionado en los artículos 29, 30 y 31 de dicho cuerpo de ley.

II. La emergencia nacional, prevista y sancionada en el artículo 221 inc. $2^{\circ}$ de dicho cuerpo de ley.

El común denominador entre ambas es su utilitarismo para gestionar y repeler aquellos hechos humanos o desastres naturales que puedan poner en peligro los elementos y condiciones esenciales de nuestro sistema constitucional, cuando exista la posibilidad de que se presente una amenaza para el mismo el mismo más allá de un punto tolerable. En ese orden de ideas, debemos concatenar la normativa de primer rango con lo estipulado y regulado en la norma secundaria, específicamente en la Ley de Protección Civil, Prevención y Mitigación de Desastres (LPCPMD), que también tiene una finalidad reactiva frente a los desastres, específicamente en la declaración de emergencias estipulada en el art 24.

El régimen de excepción, como todo elemento extraordinario de restricción constitucional, contiene condiciones específicas de aplicación. El art. 29
Cn. establece que, en los casos de guerra, invasión del territorio, rebelión, sedición, catástrofe, epidemia, de graves perturbaciones del orden público u otra calamidad general, podrán suspenderse las garantías establecidas en los artículos 5, 6 inciso primero, 7 inciso primero y 24 de esta Constitución, excepto cuando se trate de reuniones o asociaciones con fines religiosos, culturales, económicos o deportivos. Tal suspensión podrá afectar la totalidad o parte del territorio de la República, y se hará por medio de decreto del Órgano Legislativo o del Órgano Ejecutivo, según el caso. Asimismo, pueden suspenderse las garantías contenidas en los Arts. 12 inciso segundo y 13 inciso segundo de la Constitución, cuando así lo acuerde el Órgano Legislativo, con el voto favorable de las tres cuartas partes de los diputados.

De la lectura de la misma disposición se plantea el requerimiento de lo extraordinarias, anormales y temporarias que deben ser las circunstancias en tanto que supuestos habilitantes para la adopción de un régimen de excepción, de acuerdo a la jurisprudencia (sentencia de inconstitucionalidad 15-96). Es menester comprender que dentro de dichas circunstancias meritorias de un régimen como el citado figura la pandemia global del COVID-19, la cual es un hecho notorio y así declarado por la Organización Mundial de la Salud. El único elemento objetivo requerido en su declaratoria es que la misma afectare a El Salvador, lo cual así fue.

El régimen de excepción puede ser adoptado por la Asamblea Legislativa o por el Consejo de Ministros, si se trata de la suspensión a la que se refiere el art. 29 inc. $1^{\circ}$ Cn. - la de los derechos reconocidos en los arts. 5,6 inc. $1^{\circ}, 7$ inc. $1^{\circ}$ y $24 \mathrm{Cn}$. Si se trata de la Asamblea Legislativa, debe hacerlo de manera justificada, en votación nominal y pública con los dos tercios de votos, por lo menos, de los diputados electos art. (131 ord. $27^{\circ} \mathrm{Cn}$.). Por otro lado, si se trata del supuesto establecido en el art. 29 inc. $2^{\circ} \mathrm{Cn}$. - suspensión de los derechos establecidos en los arts. 12 inc. $2^{\circ}$ y 13 inc. $2^{\circ} \mathrm{Cn}$., tal disposición sólo confiere competencia a la 
Asamblea Legislativa para que adopte esta modalidad de régimen de excepción. La competencia del Consejo de Ministros para adoptar el régimen establecido en el art. 29 inc. $1^{\circ} \mathrm{Cn}$. Es de carácter excepcional, sólo cuando nuestra asamblea legislativa no sesione, solo por una imposibilidad material de la misma de hacerlo.

El principio de división de poderes (art. 86 inc. $2^{\circ} \mathrm{Cn}$.) es uno de los pilares fundamentales del Estado de Derecho y del constitucionalismo. Su función es evitar la concentración de poder en desmedro de los derechos de las personas, y su a favor se justifica la finalidad de la existencia del estado. Consecuentemente, se establece el concepto clásico de que las funciones del ejercicio del poder estatal deban dividirse entre distintos funcionarios u órganos a los que se les confiere alguna de las funciones esenciales del Estado: legislar, administrar o juzgar (sentencia de 13-111-2006, Inc. 27-2005).

Asimismo, se requiere de la existencia de mecanismos de colaboración (principio de colaboración [art. 86 inc. $1^{\circ} \mathrm{Cn}$.]) e, incluso, de controles recíprocos en el ejercicio de las funciones públicas por parte de los órganos del Gobierno y del Estado. Aquí es donde tiene sentido que el ordenamiento jurídico delimite claramente, por una parte, el ámbito de actuación de cada órgano o funcionario $y$, por el otro, de los mecanismos de control, para evitar interferencias o invasiones en las competencias que atañen a una entidad. Para cumplir tal cometido, la Constitución establece el principio de legalidad, según el cual los funcionarios del Gobierno no tienen más facultades que las que expresamente les da la ley (art. 86 inc. $3^{\circ} \mathrm{Cn}$.).

El control constitucional se compone de diversas formas y facetas, bajo un objetivo marcado: lograr el efectivo el principio de limitación del poder. Tal propósito implica la existencia de otras formas de control constitucional, diferentes al judicial, que es ejercida por la sala de lo constitucional. El control judicial representa la última instancia, y consecuentemente las resoluciones de la misma adoptan un carácter definitivo.
La doctrina constitucional reconoce dos formas de control:

I. El control intraorgánico: se produce al interior de la organización de un órgano. Es el caso del sistema de recursos o medios impugnativos en el Órgano Judicial, fuera del cual es imposible asumir la revisión, modificación, confirmación o anulación de una sentencia o resolución judicial proveniente de otro tribunal (art. 17 inc. $1^{\circ} \mathrm{Cn}$.).

II. El control interorgánico: ejercido de un órgano a otro. Tal como ocurre con el veto presidencial (art. $137 \mathrm{Cn}$.)29, la 20 Sentencia de 20 de enero de 2009 y la inconstitucionalidad 84-2006.

La sentencia de Inc. 17-2001 en su momento estableció que los controles intraorgánicos funcionan dentro de la organización de poder estatal y los controles interorgánicos funcionan entre diversos funcionarios que cooperan en la gestión estatal, los cuales pueden ser de dos clases: la colaboración, que ocurre cuando los detentadores del poder están estructurados constitucionalmente de tal manera que, solo ejerciendo conjuntamente, pueden llevar a cabo sus competencias, de modo que comparten el ejercicio de la función y, por ello, se controlan mutuamente; y, por el otro lado, la intervención constitucionalmente autorizada, con arreglo, a la cual un detentador del poder queda habilitado para intervenir en la actividad de otro órgano estatal.

Una de las competencias conferidas al Órgano Legislativo es la de limitar derechos fundamentales o la de suspenderlos de forma general, con alcance en la totalidad o en parte del territorio (arts. 29, $131 \mathrm{~N}^{\circ}$ 5 y 246 Cn.). En El Salvador, es aplicable la Convención Americana sobre Derechos Humanos, que también sujeta a la reserva de ley la limitación y suspensión de derechos (arts. 4.2, 7.2, 9, 12.3, 13.2, 15, 16.2, 21.2, 22.3 y 27). De igual forma, la constituyente limitó el ejercicio de las competencias del 
Órgano Ejecutivo que inciden en la limitación o suspensión de derechos fundamentales.

Respecto de lo primero, tal mecanismo se desarrolla mediante la sujeción a la ley. Respecto de lo segundo, teniendo en cuenta, por ejemplo, que la competencia para decretar regímenes de excepción por parte del Consejo de Ministros sólo podría ejercerse cuando la Asamblea Legislativa no esté reunida (Sentencia 29 de 9 de diciembre 2019, controversia 1-2019). 30 Sentencia de inconstitucionalidad 16-98, Sentencia de 23 de enero de 2015, inconstitucionalidad 53-2012.

\subsection{Afectaciones de derechos constitucionales y humanos durante la pandemia COVID-19}

Fue un hecho notorio que, para la gran mayoría de países latinoamericanos, el fenómeno del COVID-19 evidenció una latente falta de preparación en los efectos materiales de la protección de los derechos de salud de la población y también en la hiperproducción normativa, generalizada como un camino para pretender contener su avance y afectación. El Salvador no fue la excepción y de ahí la declaración de emergencia y estado de excepción, que generó más de 90 cuerpos normativos que incluyen Decretos Legislativos que emanaron de los diferentes órganos del estado.

Bajo ese contexto, no es imprescindible hacer una referencia puntual a todos y cada uno de los decretos, algunos transitorios, los cuales fueron expulsados del ordenamiento jurídico en su momento por los órganos competentes en razón a su incongruencia con la normativa constitucional, en el ejercicio de los controles de dicha naturaleza. Es menester del presente documento hacer referencia a los fenómenos de abusos de hecho y normativos que se realizaron por parte de los cuerpos policiales, bajo el supuesto amparo de una normativa secundaria defectuosa que generó una serie de consecuencias palpables para la población salvadoreña y una sala de lo constitucional, que tuvo que multiplicarse al máximo para dar cumplimiento a su deber de control normativo constitucional.

Uno de los principales fenómenos que generó esa serie de normativas, la cual inició con el ahora célebre Decreto Ejecutivo No. 12, publicado en Diario Oficial 20 de marzo de 2020, de las Medidas Extraordinarias de Prevención y Contención para Declarar el Territorio Nacional como Zona Sujeta a Control Sanitario, a fin de Contener la Pandemia COVID-19, que imponía una cuarentena domiciliaria obligatoria, se tradujo en una constante de abusos (Human Righs Watch, https://www.hrw. org/ visto 18/11/2020), cometidos por la policía nacional civil. En pocas semanas fueron arrestadas centenas de personas en cumplimiento de las restricciones impuestas por el gobierno, dichas personas eran trasladadas a "centro de contención".

Solo durante la noche del domingo 22 de marzo, a nivel nacional, se dio la detención de 269 personas por no acatar la medida de cuarentena domiciliaria (visto el 18/11/2020 en https://elfaro.net/). En los primeros días de abril, la Procuraduría de Derechos Humanos recibió más de 300 denuncias por abusos de esa naturaleza (visto el 18/11/2020, en https://www. elsalvador.com/ ).

El 26 de marzo, la Sala de lo Constitucional de la Corte Suprema (Habeas corpus 1482020) sentó las bases para resoluciones futuras en las que aquellas medidas de capturas y detenciones arbitrarias no tendrían sustento jurídico en ningún caso por infringir la supuesta cuarentena normativa. Lo anterior no impidió que hasta abril se presentaran más de 4000 detenidos en 87 centros de contención gubernamentales (Human Righs Watch, https://www.hrw.org/ visto 18/11/2020). En dicha resolución se determinó que solo se podía confinar a una persona en un centro de contención si se podía determinar objetivamente que había estado expuesta al virus y no simplemente por circular en la vía pública.

Dentro de muchísimas resoluciones dadas bajo el control de constitucionalidad 
por la Sala de lo Constitucionalidad de la Corte Suprema de Justicia, (Art. 174 Cn , el ente competente de acuerdo a la carta magna salvadoreña para conocer y resolver las demandas de inconstitucionalidad de las leyes, decretos y reglamentos, los procesos de amparo, el habeas corpus, las controversias entre el Órgano Legislativo y el Órgano Ejecutivo a que se refiere el Art. 138 y las causas mencionadas en la atribución 7ạ del Art. 182 de esta Constitución, mencionaremos las 2 principales claves para revertir el desorden normativo que generó un caos de incertidumbre jurídica tanto a los juristas como a la población común. Lo anterior con el fin de restablecer y tutelar aquellos derechos humanos constitucionalmente protegidos que estaban siendo violentados.

El 8 de junio de 2020 se dio la primera resolución clave, por parte de la SC, para corregir lo que ya se podía determinar como un abuso normativo por parte del ejecutivo y como deficiencias estructurales de los cuerpos legislativos, mediante resolución del proceso referencia 21/23/24/25-2020. En ella se declararon inconstitucionales los decretos ejecutivos $\mathrm{N}^{\circ} 5,12,14,18$, $19,21,22,24,25,26$ y 29 , referentes a la cuarentena domiciliaria obligatoria, así como determinaron la Ley de Restricción Temporal de Derechos Constitucionales Concretos para Atender la Pandemia COVID-19, y la Ley de Regulación para el Aislamiento, Cuarentena, Observación y Vigilancia por COVID-19. Gracias a la resolución mencionada se puso fin a 80 días de cuarentena y confinamiento a la población en general. De acuerdo con dicha Sala, no se justificaron adecuadamente las razones por las cuales fue necesario suspender los derechos constitucionales y usurpar funciones legislativas por parte del órgano ejecutivo, en lo referente a normar suspensión de derechos y garantías constitucionales, atribución eminentemente legislativa (art 131 y sigs. Cn.)

El 7 de agosto de 2020 se dio la segunda resolución clave por parte de la SC en lo referente a la reactivación económica, dejando sin efecto el decreto ejecutivo No. 32.- Protocolos Sanitarios para Garantizar los Derechos a la Salud y a la Vida de las Personas, en el Proceso de Reactivación Gradual de la Economía, durante la Pandemia por COVID-19, aplicable en las Zonas Occidental, Central y Oriental de la República de El Salvador, publicado en el Diario Oficial 29 de julio de 2020 (inc.21/23/24/25-2020). La publicación mencionada también contenía la calendarización del plan de reactivación económica e incorporó otros aspectos del manejo de la pandemia del COVID-19, estableciéndose que dicha normativa contradecía parámetros constitucionales relacionados con la suspensión y limitación de derechos fundamentales, afectando manifestaciones importantes del derecho a la libertad y del ejercicio de otros derechos fundamentales. La suspensión de derechos constitucionales sólo puede surgir de un decreto Legislativo que autorice un régimen de excepción y aun en ese caso, muchas manifestaciones del derecho a la libertad no pueden ser suspendidas en un régimen de excepción, mucho menos mediante normativa proveniente del órgano ejecutivo (que es lo que el titular de dicho órgano había realizado y fue objeto de control de la citada sala).

La resolución incluso llegó más allá al indicarle al ejecutivo que, de persistir en emitir a futuro normativas similares, las mismas no producirían efecto jurídico constitucional ni legal alguno.

\section{CONSTRUCCIÓN DEL CONSTITUCIONALISMO DESDE LAS PREMISAS EXISTENTES}

En este apartado abordaremos brevemente la perspectiva regional, desde Centroamérica, como apuesta de solución a los problemas humanos ocasionados por falta de protección de algunos derechos.

Es necesario replantear libremente la creación de mecanismos de protección universal. La improbabilidad política precisa ser distinguida de la imposibilidad teórica, al punto que la falta de voluntad no limite la libertad de pensar. 
Con las premisas existentes sobre protección de los derechos humanos que reconozca un constitucionalismo universal, nos referimos al camino ya recorrido a lo largo de la vida del ser humano. Las premisas son los derechos generalmente reconocidos en tratados sobre derechos humanos universales y regionales. Ambas perspectivas pueden verse enriquecidas mutuamente, por ejemplo, la perspectiva universal de los derechos humanos puede enriquecerse a partir de la experiencia regional de protección de datos personales llevada a cabo en la Unión Europea.

\subsection{Constitucionalismo Regional en germen desde Centroamérica}

El Sistema de Integración Centroamericana (SICA), fundado por los países de la región (Guatemala, El Salvador, Honduras, Nicaragua, Costa Rica, Panamá) busca asegurar el irrestricto respeto de los derechos humanos, art. 1 del Protocolo de Tegucigalpa. Para ello se realizó una integración para hacer un frente común a los desafíos de similares, mediante la firma de este tratado el 13 de diciembre de 1991. Posteriormente se unió Belice (2000) y República Dominicana (2013).

Los países centroamericanos deben verse como Estados interesados en promover las iniciativas tendentes a reconocer derechos de las personas, porque sus nacionales requieren cada vez más de protección. Las naciones centroamericanas experimentan esa misma realidad: masas de su población se migran a otros países bajo la promesa de encontrar un futuro mejor. Centroamérica ya cuenta con instrumentos para luchar conjuntamente frente a los retos de salud, por ejemplo: Centroamérica compró medicinas conjuntamente para abastecer su sistema de salud Sistema de Integración Centroamericana en el año 2013 (SICA).

Por el contrario, Centroamérica, durante la pandemia COVID-19 no se mostró suficientemente unida. El cierre de fronteras se realizó por cada país en diferentes fechas e intensidades. Lo anterior puede ser entendido históricamente, porque Centroamérica no ha respondido en conjunto frente a los desafíos de la migración, el comercio exterior, entre otros, tal como lo comenta diáfanamente la doctrina política (Parthenay, p. 7 y 8).

Sin embargo, Centroamérica es conocida como una región resiliente, que siempre busca la manera de integrarse (Parthenay, p. 10).

Cabe mencionar que, de forma paralela, a nivel regional, la Unión Europea, mediante el art. 168 Tratado de Funcionamiento de la Unión Europea, establece que la Unión definirá y ejecutará sus políticas para garantizar un alto nivel de protección de la salud humana, y complementará las políticas de cada uno de los Estados nacionales. Asimismo, la Unión fomentará la cooperación entre los Estados miembros de la misma. Sin embargo, durante la primera oleada de la pandemia COVID-19, en la UE, cada país adoptó estrategias diferentes para mitigarla.

Desde América debería de impulsarse un constitucionalismo de derechos de migrantes, que compense la desigualdad que provoca el traslado de la riqueza mediante los tratados de libre comercio. Por ejemplo, el germen de este constitucionalismo se puede encontrar en los tratados bilaterales de reconocimiento de derechos de seguridad social suscritos entre España con países latinoamericanos, los acuerdos por los cuales se ha permitido "cuotas" de migrantes de países suramericanos a territorio español.

\subsection{Reconocimiento de la protección de derechos humanos desde los tratados y jurisprudencia americana}

El Salvador es un país integrante de lo que en este trabajo llamamos la periferia del mundo, por alusión a la existencia de los países ejes del mundo o potencias mundiales en la economía y otros aspectos del desarrollo humano. El Salvador, al igual que muchos países, está integrado en un sistema jurídico universal y uno regional de respeto y protección de derechos humanos. En el caso de América Latina, basta señalar que por regla general se aplica el sistema universal 
de Derechos Humanos que la Organización de las Naciones Unidas promueve y, además, el sistema regional, promovido por la Organización de Estados Americanos. Estos sistemas contienen derechos generalmente reconocidos en el mundo, recogidos en otros tratados similares y en constituciones.

El relanzamiento de los derechos humanos a nivel mundial, repensados a partir de las necesidades actuales, de crisis del COVID-19 constituye una oportunidad para valorarlos y agregar otros, como, por ejemplo, el derecho a recibir "el pan de cada día" o el mínimum vital o la protección de datos personales, entre otros.

La reflexión colectiva de los derechos humanos a escala puede realizarse por los medios de comunicación actuales.

\subsection{Los medios de comunicación y tecnológicos como instrumento de participación constitucional}

Los medios de comunicación han sido ya utilizados para derrocar gobiernos. La primavera árabe, la manifestación de los indignados en España, entre otras manifestaciones universales han puesto a prueba la reacción de colectivos humanos que exitosamente se han movilizado. Varios medios de comunicación online informaron de catástrofes y otros conflictos sociales en Venezuela y Nicaragua. El presidente Trump y otros mandatarios están empleando el Twitter como medio de comunicación oficial y conducen su discurso, volviéndolo unívoco.

El empleo de los medios de comunicación tuvo efectos impredecibles en un primer momento en la primavera árabe, aunque hoy en día pueden serlo mediante el empleo del Big data, mediante la recopilación masiva y análisis constante de datos para predecir el comportamiento humano (Morozov, 2014, p.18). Morozov también critica el papel de los gigantes digitales y al mismo gobierno estadounidense por actuar hipócritamente al permitir el empleo de los medios de internet por gobiernos con credenciales cuestionables.
Millones de seres humanos tienen cuentas en Facebook, Twitter, Instagram y otras redes sociales. En El Salvador, Google ha sido calificado como el buscador por excelencia. Ahora bien, los seres humanos que desean participar de los beneficios de estas redes deben aportar como moneda de cambio sus datos personales. De ahí que el ejercicio de los derechos vitales de poblaciones enteras no depende de primera mano de un estado, sino, también, de la actuación de un gigante tecnológico.

Si una persona desea reportar el robo de su identidad en Facebook debe dirigirse a esta plataforma, y en caso de negativa lo hará el Estado, si es que se encuentra preparado. En España, por fortuna, la Agencia Española de Protección de Datos tiene una línea telefónica de emergencia para solventar asuntos de ciberacoso y otros incidentes similares, aunque si el hecho constituye un delito remiten a la persona a la Policía Nacional para que tome cartas en el asunto. Sin embargo, hay países que ni siquiera tienen legislación de protección de datos personales, este es el caso de El Salvador, el cual está en etapa de construcción.

Sin embargo, no hay que destacar resultados felices con la sola promulgación de una legislación que regule un derecho en un Estado, pues la protección efectiva de los derechos no depende de esto sino de la auténtica fuerza mental y convicción de reconocer los derechos en serio, con esto basta muchas veces para solventar los problemas, aunque carezcan leyes que regulen las prerrogativas a favor de las personas. Sobradamente se conoce que, en Argentina, la jurisprudencia de los jueces en materia de Derecho de familia, entre otras, iba a la vanguardia de la entonces vetusta legislación civil y comercial, hasta la aprobación de la reciente legislación sobre estas materias, que por cierto, constitucionalizó estos derechos. Se sabe que otros estados latinoamericanos promulgan leyes e instauran organismos estatales que no hacen más que engrosar la burocracia e incrementar el presupuesto del Estado, sin proporcionar resultados efectivos por falta 
de esta convicción sobre el cumplimiento del deber.

Otro ejemplo reciente es el empleo de medios de comunicación para expresar la parodia como forma de diatriba a la política interna, como voz de grandes masas de la población y al parecer en un gran porcentaje de la diáspora de varios países, entre esos, El Salvador, para expresar su inconformidad con la política tradicional y que constituye otro de las realidades a las que Morozov ya se refería en su obra: "The Net Delusion". Estos ejemplos, entre muchos otros, constituyen escenarios que validan la idea de que debemos hacer un frente común ante problemas que nos aquejan a todos en el mundo.

\section{PUESTA EN PRÁCTICA DEL CONSTITUCIONALISMO UNIFORME DESDE LOS PRINCIPIOS COMUNES (A MANERA DE ESBOZO)}

En este apartado esbozaremos la idea de promover un constitucionalismo basado en principios comunes a todas las naciones y Estados, de modo que dé lugar a reconocer un texto único y por tanto uniforme a todas las naciones, a manera de soft law, es decir, de un documento no vinculante jurídicamente $\mathrm{y}$ que constituya un antecedente para conformar un documento de hard law, mediante un tratado internacional. Un documento de soft law podría ser reconocido por la humanidad entera sin pasar por los parlamentos ni por las administraciones públicas de los Estados, bastaría su reconocimiento por redes sociales.

\subsection{Mínimo común vital (Alberto Masferrer)}

La renta básica universal es una necesidad humana que recientemente ha sido instalada en España, en plena pandemia, y que Alemania está planeando instaurar también en la presente coyuntura ${ }^{1}$. Al respecto, este

1. FERRAJIOLI, Luigi; Minuto 1 hora con 4 minutos del video https://www.youtube.com/ watch?v=sPPQjcXLbyo apartado busca reivindicar a uno de los pensadores salvadoreños, al profesor Alberto Masferrer, quien escribió su obra titulada: “El mínimum vital" en el año 1929, calificada como doctrina de pensamiento reconocida por varios pensadores del siglo pasado.

Masferrer sostenía que todo estaba interconectado, o, más bien, que todos los actos humanos son interdependientes. Ya en aquel entonces Masferrer reconocía la aplicación de la teoría darwinista en las sociedades humanas, donde el más "apto" se come al menos, que muchas veces resulta ser el más egoísta y descorazonado (p.12), que al final de cuentas genera conflictos en la sociedad; y agrega que la humanidad entera se ha afiliado en dos sectores irreconciliables, la de los que padecen y odian así como añoran venganza y la de quienes gozan, atesoran y defienden la realidad con represión (p.13).

Masferrer revela que, en medio de las "horas de lobos", hay hombres que sí sienten la vida y reivindican espiritualmente el esfuerzo propio en la obtención de riqueza para el rico y dice: "conténtate con que se te dé libertad para convertir en oro el árbol y la piedra, pero no la miseria, no el hombre, no la salud, no la sangre de tus hermanos" (p.14), e incita al trabajador a que edifique su propia fortuna por su propio esfuerzo, contentándose con aquello indispensable para vivir.

Masferrer, al igual que Humboldt, ve interdependencia en toda la naturaleza y el hombre es parte de ella. Ambos autores buscan el equilibrio de las cosas, pues un desequilibrio afecta la existencia de otros.

\subsection{El llamado a la intervención externa a solventar conflictos internos}

Se sabe que los ciudadanos desfavorecidos por las medidas de un gobierno en turno, ya sea que pertenezcan a la diáspora o vivan dentro del país, piden o añoran la intervención de un suprapoder externo que tenga injerencia en el gobierno de su país. En el caso de El Salvador, el Frente Farabundo Martí para la Liberación Nacional 
pidió a la Organización de Naciones Unidas que interviniera en el conflicto armado durante la década de los ochenta y principios de los noventas, esfuerzo internacional que constituyó un ejemplo vendido como solución de otros conflictos sociales internos por dicho organismo.

Los ciudadanos de un país manifiestan su descontento ante un gobierno y piden la intervención de otros para reivindicar sus derechos, por ejemplo, los venezolanos se manifiestan masivamente en las calles de Madrid y lo hacen libremente, porque muchos de ellos cuentan con doble nacionalidad (venezolana y europea).

\subsection{Un nuevo constitucionalismo desde la ciudadanía cosmopolita}

Las personas quieren trabajar. El trabajo dignifica a las personas. La tierra es de todos y consecuentemente, el género humano debería de vagar libremente si quisiera. Ahora bien, ¿qué conductas deben frenarse para evitar la perturbación de la paz por la libre circulación del género humano? Las delictivas o las que no cumplan un mínimo ético que ponga en riesgo la convivencia.

El ciudadano debería ser del mundo, por lo que en este punto es crucial citar al profesor mexicano (Santiago, p.5 y 6), quien siguiendo a Kant explica que la novedad del proyecto kantiano, ya desde el año 1795 , es considerar al hombre como parte de la comunidad mundial, sin limitarlo a fronteras, dotándolo de un carácter universal y acuñando la carta de ciudadanía cosmopolita, además de sostener "La Paz perpetua", para lo cual deben instaurarse bases de instituciones en el ámbito internacional. Dicha ciudadanía se adecuaría a la Federación de Estados como parte de una estructura encaminada a obtener una paz cosmopolita (Santiago, p. 8).

De este fenómeno derivan hechos como que en El Salvador, al igual que en otros países, se está muy pendiente de las elecciones presidenciales en Estados Unidos de América, por cuanto su resultado tiene una incidencia en la política nacional y es susceptible de condicionar la suerte de al menos al menos un millón de los tres millones de salvadoreños residentes en este país del norte.

Coincidimos con la doctrina latinoamericana de que es posible, hoy en día, configurar una ciudadanía mundial "o cosmopolita planteando un tipo de ciudadanía a medio camino entre lealtades distintas", entre la que se deba al estado nacional de origen y a otra adquirida posteriormente (Santiago, p. 16). Ello le sucede a los más de tres millones de salvadoreños que conforman la diáspora en todo el mundo, datos que solamente recogen desde el año 1990 al 2019, a lo que habría que sumar las migraciones sucedidas en los años 70 y 80. La mayoría de emigrantes pertenecen al género masculino, en un 99.3 $\%$, aunque hay excepciones por destino, entre los que se encuentran Costa Rica, México y España, con predominio del género femenino (CEPAL, p. 3).

\subsection{Servicios sociales de confianza a disposición de la diáspora}

Los poderes públicos centroamericanos podrían ponerse de acuerdo para ofrecer servicios sociales a favor de los centroamericanos que vivan dentro de sus fronteras o fuera de ellas. Es posible perfilar, fácilmente, los lugares de destino de la migración centroamericana y con ello proveerles servicios de apoyo para solventar sus problemas tanto jurídicos, de salud, educativos, entre otros.

El triste e igualmente célebre caso de los niños y niñas del triángulo norte centroamericano, conformado por los países de Guatemala, El Salvador y Honduras, que viajan con destino a Estados Unidos de América, los nicaragüenses y hondureños, seguidos de salvadoreños que viven en Europa, Canadá, Australia y Suecia. Los ciudadanos centroamericanos tienen al menos una identidad regional que los vuelve más iguales y por tal motivo, ante la orfandad de asistencia de sus propios gobiernos acuden a los consulados de otros países centroamericanos, asistencias que se han visto hasta para realizar festividades con motivo de la independencia de los españoles. 
El ideal de una patria centroamericana ha sido incluido literalmente en la Constitución salvadoreña en su art. 89. Sabido es que hermanos hondureños y nicaragüenses han disfrutado con regularidad de servicios de educación y salud, entre otros en suelo salvadoreño, sin que las distancias no despreciables entre su lugar de residencia y el de asistencia haya constituido motivo para rechazar la calidad del servicio salvadoreño, proporcionado sin reparo alguno, incluso gratuitamente. Es decir, los servicios de salud han sido prestados como si fuesen prestaciones universales a nacionales de otros estados centroamericanos. Entre 2013 y 2017, El Salvador prestó 91, 000 consultas a extranjeros, y el $97 \%$ de estos son hondureños y guatemaltecos (Plaza Pública, 2018).

La protección social constituye un elemento fundamental para una estrategia de desarrollo, así se reconoce en un estudio financiado por la Unión Europea, enfocado precisamente en cuatro países centroamericanos: El Salvador, Guatemala, Honduras y Nicaragua. El sistema de protección social debe ser integrado y sostenible, ya que la seguridad social ha sido incapaz de proporcionar cobertura a la población total, pues básicamente da cobertura a empleados formales asalariados y urbanos, excluyendo al informal y rural que forman la mayor parte de estos países (MesaLago y De Franco, 2010, p. 63 y 64).

La Comunidad internacional de donantes juega un papel importante en el quehacer de apoyo en la lucha contra la pobreza, lo que puede servir de base para sufragar los costos de la concreción de los derechos de una ciudadanía cosmopolita.

\section{a) Servicios de notariado}

Convendría iniciar este constitucionalismo desde un plano regional con miras a universalizarlo. Por ejemplo, en el caso de Centroamérica, precisamente en el marco del SICA, existen valores que indican el reconocimiento de intereses humanos comunes reconocidos a nivel político que, llevados a la práctica, pueden traducirse en beneficios más palpables para los centroamericanos. Por ejemplo, tanto El Salvador como Costa Rica permiten el ejercicio del notariado en el extranjero. Lo anterior representa un beneficio para los salvadoreños que residen en el exterior, ya que pueden acceder a servicios jurídicos sin tener que traspasar las barreras culturales que supone vivir en el extranjero.

\section{b) Convenios multilaterales de seguridad social}

A pesar de las limitantes ya esbozadas en cuanto a la garantía de los costos de salud de los ciudadanos de los cuatro países centroamericanos, se han promovido convenios bilaterales y multilaterales de seguridad social entre países iberoamericanos.

El Convenio Multilateral Iberoamericano de Seguridad Social y su Acuerdo de Aplicación constituyen un instrumento por el cual se busca coordinar las relaciones en materia de seguridad social en la región iberoamericana, para proporcionar cobertura social a los trabajadores de los Estados involucrados. El convenio está vigente en España desde el año 2011 y está abierto a toda la Comunidad Iberoamericana. A la fecha son once Estados los que lo aplican, entre estos, España, El Salvador, Chile, Argentina, Bolivia, Brasil, Ecuador, Paraguay, Perú, Portugal y Uruguay (Instituto de la Seguridad Social, Gobierno de España, 2017).

Otros Estados iberoamericanos pueden sumarse a este esfuerzo multilateral.

\section{CONCLUSIONES}

Ahora más que nunca los habitantes de este mundo estamos interconectados. Las acciones u omisiones de algunos repercuten en otros, lo cual quedó evidenciado en los orígenes y manejo sectorizado de la pandemia del COVID-19. La tierra es un recurso que compartimos como especie, y la vida en la misma se está reorganizando, y dentro de esta cabe meditar seriamente en que debemos ser cada día más responsables y consecuentes como colectivo, lo cual supone que reconozcamos nuestra humanidad. El desarrollo individual debe ser compatible 
con el colectivo. Los humanos en el mundo tenemos herramientas de comunicación que permiten entrelazar nuestras ideas y encontrar puntos en común con otros.

Estas ideas en común pueden incluir el relanzamiento de derechos humanos y su ejecución mediante mecanismos de cooperación entre personas, empresas y Estados. Las asociaciones entre Estados pueden incluir mecanismos de distribución de los beneficios que se generan con la riqueza obtenida mediante el trabajo concienzudo. Un aspecto clave en el reconocimiento de una nueva constitución es la educación integral en valores de derechos humanos.

Es preciso reconocer más derechos humanos, fundamentales para desempeñar una vida digna en el planeta, lo cual no debe quedar como un esfuerzo superfluo normativo, sino que goce del debido acompañamiento en su aplicación.

La pandemia nos ha enseñado y sigue enseñando cómo valorar más la vida, la salud y otros derechos. Muchas generaciones en el mundo no conocían el significado del riesgo de perder la vida en un instante, lo que en algunos lugares del mundo se vive cotidianamente. El reconocimiento de los derechos humanos mínimos, a nivel global, debe constituir una reflexión constante en un mundo en cambio permanente.

Los Estados ubicados en la periferia del mundo experimentan los efectos de las acciones producidas en Estados ubicados en el "centro del mundo", donde se toman las decisiones que inciden mundialmente. Los costos sociales que derivan de este mecanismo constituyen una de las razones por las cuales, desde la periferia, las necesidades se pueden convertir en reivindicaciones, $y$ las migraciones constituyen una de estas manifestaciones.

En fin, hay muchos temas que valorar y discutir, las redes sociales y los medios informáticos pueden constituir instrumentos para exponer nuestras ideas, sin pretender tener la última palabra al respecto.

\section{REFERENCIAS BIBLIOGRÁFICAS}

» CEPAL. (2013). Migrantes salvadoreños en el exterior: Tendencias, perfiles, métodos de estimación. Resumen ejecutivo. Recuperado el 01 de octubre de 2020 de: file:///Users/elenaconde/Downloads/Informaci\%C3\%B3n_sobre_SAI_2192019_(1)._Resumen_Ejecutivo.pdf

$»$ Centro para el Control y la Prevención de Enfermedades. (s.f.) Recuperado el 03 de octubre de 2020 de: https://n9.cl/5zlb7

» Constitución de la República de El Salvador. (1983).

» Diario Oficial de la Unión Europea. (2010). Tratado de Funcionamiento de la Unión Europea. Recuperado 25 de octubre de 2020 de:

» https://www.boe.es/doue/2010/083/Z00047-00199.pdf

» EL FARO (El Salvador). (s.f.). Recuperado el 08 de octubre de 2020 de: (https:// elfaro.net/)

» EL SALVADOR (El Salvador) ( s.f.). Recuperado el 09 de octubre de 2020 de: en (https://www.elsalvador.com/)

» El PAÍS. (2020) Luigi Ferrajoli, filósofo: Los países de la UE van cada uno por su lado defendiendo una soberanía insensata. Recuperado el 02 de noviembre de 2020 de: https://n9.cl/uzph7

» Expansión. Datosmacro.com. (s.f.) Recuperado el 21 de octubre de 2020 de: 
https://datosmacro.expansion.com/demografia/migracion/emigracion

» Fernández García, Antonio. (2000). La controversia sobre Pío XII y el holocausto. Cuadernos de Historia Contemporánea, (22), 359 - 374.

» Ferrajoli, L. (s.f.) Conversatorio con Luigi Ferrajoli: la esfera pública post covid-19.

» Recuperado el 25 de octubre de 2020 de: https://www.youtube.com/ watch?v=sPPQjcXLbyo

» Human Rights Watch. (s.f.). Recuperado el 18 de octubre de 2020 de: https:// www.hrw.org/

» Imprenta Nacional. (2020) Recopilación de Decretos Covid 19 El Salvador. (24 de agosto de 2020). Recuperado el 23 de octubre de 2020 de: https://n9.cl/owyl

» Mayor Ferrándiz, T. Ma. (2011). El silencio de las iglesias católica y protestantes ante el holocausto. Revista de Claseshistoria (s.n.): 1 - 31. Recuperado el 26 de octubre de 2020 de: http://www.claseshistoria.com/revista/index.html

» Masferrer, A. (1968). El MINIMUN VITAL. San Salvador: Ministerio de Educación. Recuperado el 26 de octubre de 2020 de: http://biblioteca.utec.edu.sv/siab/ virtual/libros_PDF/Minimun_vital.pdf

» Mesa-Lago, C. y De Franco, M. (2010). Estudio sobre la protección social en Centroamérica. Volumen I. Informe General (El Salvador, Guatemala, Honduras y Nicaragua). IBF International Consulting; BAA (España), Unión Europea. Recuperado del 15 de octubre de 2020 de: https://n9.cl/ro6f

» Ministerio de trabajo, migraciones y seguridad social. Instituto Nacional de la Seguridad Social. Gobierno de España. (2017). Convenios Bilaterales y multilateral iberoamericano de seguridad social 2017. Recuperado el 06 de octubre de 2020 de: https://n9.cl/9wc08

» Morozov, E. (s.f.) “The internet, Politics, and the Politics of Internet." En Ch@ nge 19 key essays on how Internet is changing our lives. BBVA. Recuperado 12 de octubre de 2020 de: https://n9.cl/fmn0m

» Morozov, E. (2011) The Net Dilusion. How not to Liberate the World. Recuperado 6 de octubre de 2020 de: https://n9.cl/dc9n6

» Parthenay, K. (2020). El regionalismo centroamericano ante el nuevo orden mundial: entre pragmatismo y crisis. Análisis Carolina, (6), 1 - 12. ISSN: 2695-4362

» https://doi.org/10.33960/AC_6.2020.

» Plaza Pública. (2018). Miles de guatemaltecos y hondureños acuden a El Salvador por servicios de salud. Recuperado el 06 de octubre de 2020 de: https:// n9.cl/7temf

» SICA (Sistema de Integración Centroamericana). (1991). PROTOCOLO DE TEGUCIGALPA A LA CARTA DE LA ORGANIZACION DE ESTADOS CENTROAMERICANOS (ODECA). XI CUMBRE DE PRESIDENTES CENTROAMERICANOS. Recuperado 8 de octubre de 2020 de: https://n9.cl/tvodj

» SICA (Sistema de Integración Centroamericana). (2013). La compra conjunta de medicamentos, un avance en los sistemas de salud en Centroamérica. Recuperado 8 de octubre de 2020 de: https://n9.cl/k3wl

» Santiago, J. R. (2009). Ciudadanía cosmopolita y globalización. Una revisión del 
pensamiento kantiano. Universitas. Revista de Filosofía, Derecho y Política, (9): 5 20. Recuperado 15 de octubre de 2020 de: https://n9.cl/hdhex

» Sala de lo Constitucional de El Salvador. (2001). Sentencia de 23 de marzo de 2001, inconstitucionalidad 8-97

» Sala de lo Constitucional de El Salvador. (2015) Sentencia de 17 de noviembre de 2015, inconstitucionalidad 105-2014.

» Sala de lo Constitucional de El Salvador. (2009). Sentencia de 20 de enero de 2009, inconstitucionalidad 84-2006.

» Sala de lo Constitucional de El Salvador. (2001). Sentencia de Inc. 17-2001.

»Sala de lo Constitucional de El Salvador. (2020). Habeas corpus 148-2020, del 16 de mayo 2020,

» Sala de lo Constitucional de El Salvador. (2020). Inconstitucionalidad 21/23/24/25-2020, del 7 de junio y 8 de agosto del 2020. 